about the 14 others except that some, if not most, of them had suffered a penetrating injury. Most centres today would perform emergency computed tomography for all such patients at their first attendance. This does not seem to have been the case in the study, since the authors claim that "none of the 20 patients who underwent computed tomography for a second time showed measurable change from the findings at the first attendance," which leads us to believe that most of the patients who were operated on had computed tomography for the first time at the time they reattended. One could thus conclude that a vault fracture is an indication for immediate computed tomography and neurosurgical evaluation rather than a predictor of computed tomographic abnormalities and surgery for patients who reattend (as the authors conclude).

Secondly, Voss and colleagues state that their data "support the continued use of selective skull radiography to identify those at high risk for intracranial complications." While we accept this statement in principle, we think that it is important to define better the criteria that emergency doctors should follow in requiring skull $x$ ray films. Surely the data presented do not disprove Masters et als recommendations that skull radiography is unnecessary in patients who present for the first time after a head injury that did not result in loss of consciousness, amnesia, or other neurological abnormalities and that these patients should be sent home with an advice sheet. ${ }^{2}$ To prevent an epidemic of unnecessary skull radiography it would be helpful to know whether any such patient was among those who underwent neurosurgery on reattendance in the authors' study.

DANIELE COEN House officer BARBARA OMAZZI House officer GIOVANNI PISTONE House officer

Accident and Emergency Service, Ospedale Civile di Rho, 20017 Rho,

Italy

1 Voss M, Knottenbelt JD, Peden MM. Patients who reattend after head injury: a high risk group. BMf 1995;311:1395-8. [With commentary by G Murray.] (25 November.)

2 Masters SJ, McClean PM, Arcarese JS, Brown RF, Campbell JA, Freed HA, et al. Skull x ray examinations after head trauma. N Engl f Med 1987;316:84-91.

\section{Authors' reply}

EdrToR,-We agree with Daniele Coen and colleagues that ideally all patients with a skull fracture or a penetrating injury should undergo computed tomography and neurological evaluation. This, however, is impossible where head injury is common or where computed tomography and neurosurgeons are scarce. If we had offered computed tomography to all our patients with penetrating wounds to the head or skull fractures who were classed as having minor head injury we would have obtained at least 10 times the number of scans, with the same yield. Generally, most of these patients go home and their problem resolves spontaneously. The purpose of our paper was not to repeat the many studies on outcome in patients after their first attendance with head injury but to try to formulate risk factors for the $2 \%$ who reattend on the basis of the advice sheet on head injuries.

We agree with Masters et al that skull radiography is probably unnecessary in most patients with blunt head trauma due to acceleration or deceleration who have no positive features such as loss of consciousness. This probably also applies to patients who are going to have computed tomography before observation in hospital. We believe that a skull fracture indicates that a nontrivial force has been applied to the head. This may be associated with intracranial bleeding, and patients merit at least careful observation even if neurologically normal. Not all patients who develop intracranial complications after head injury have an initial brain injury, and early computed tomography is unlikely to be contributory in this group.

Skull radiography is particularly valuable for departments that do not have unlimited access to computed tomography: even after losing consciousness, patients who are neurologically normal and do not have a skull fracture can usually safely be sent home immediately to the care of a responsible person, thus releasing hospital beds. If such patients reattend, however, it makes sense to perform computed tomography if features indicate that a complication has developed, irrespective of the initial presentation. Another reason for skull radiography is to detect intracranial air, a foreign body, or a slot fracture from a penetrating injury: these are important even if the patient is neurologically normal. Two of the five patients with cerebral abscess, two of the eight with extradural haematoma, and three of those with subdural haematoma who had neurosurgery were neurologically normal at their first attendance; all those who reattended were neurologically normal on discharge from their first admission.

JOHN KNOTTENBELT

Accident and Emergency Department,

Northwick Park Hospital

Harrow, Middlesex HA1 3U

Consultant

Hout Bay,

MIRANDA vosS

South Africa Medical officer

Medical Research Council,

MARGARET PEDEN

Tygerberg,

Cape,

South Africa Research scientist

\title{
Costs of prevention
}

\section{Place impossible political burden on local authorities}

EdrToR,-I submit that John Cairns does not go far enough in his editorial on the costs of prevention. ${ }^{1} \mathrm{He}$ suggests that prevention is not necessarily better or less expensive than cure. I would say that it is impossible to compare prevention and cure because the outcome measures are different. Cure is measured in terms of recovery from illness or of saving life, while prevention can be assessed only in terms of extended years of useful life, with the intended effects of intervention being explanatory variables rather than prime outcome measures.

The effects of prevention on the curative services may be immediately beneficial, but thereafter, by extending life, they are at best neutral and more likely to add to the burden. Furthermore, unless the risk is high, individual preventive measures give a low return and so are far more expensive than cure. At present, the public tacitly accepts that prevention is more expensive than cure. In his Richard Dimbleby lecture on BBC television in 1978 the late Lord Rothschild pointed out that expenditure on preventing death is related to the perceived rather than the real risk. It may be morally correct for society to decide that it is prepared to spend 10 times as much on preventing a death in a road accident $\left(£ 10^{5}\right)$ than is generally spent on cure $\left(£ 10^{4}\right)$. One questions whether this is a rational moral decision when the sum per death probably multiplies 100 -fold in the sequence road accident, railway accident, fire, and radiation. These differences put an impossible political burden on local authorities if they have to apportion one budget.

The problem must be solved centrally by a separate government allocation for health promotion. It might be possible for the same authority to coordinate services at a local level and for health promotion and treatment services to commission specific items from each other. Subject to this, the budgets must be held entirely separately and no virement allowed.

C K CONNOLLY

Darlington Memorial Hospital, Consultant physician

Darlington DL3 6HX

1 Cairns J. The costs of prevention. BMf 1995;311:1520 (9 December.)

\section{Prevention encompasses more than screening}

EDITOR,-John Cairns's editorial entitled "The costs of prevention" should more accurately have been titled "The costs of screening." Cairns perpetuates the widespread misconception that prevention consists only of screening programmes. Prevention encompasses much more than screening, as so well discussed by Rose..$^{2-4}$

Mass strategies such as the fluoridation of water, immunisation, nutrition programmes, environmental protection, a reduction in cigarette smoking, and legislation on the use of seat belts and drink-driving are also part of prevention. Certainly, all preventive programmes have costs and risks as well as potential benefits, which need to be examined critically. The balance of potential costs and benefits for mass strategies may, however, be quite different from the balance for screening strategies (which are targeted at identifying high risk individuals), as Rose has also pointed out; Cairns does not consider these at all

This title and the subtitle ("Not necessarily better than cure") in a journal such as the $B M \mathcal{F}$ may be misconstrued as applying to all preventive programmes, but the argument in the editorial is made for only one, relatively limited, aspect of prevention-screening; other aspects are ignored.

KAY-TEE KHAW

University of Cambridge Professor of clinical gerontology Addenbrooke's Hospital,

Cambridge CB2 2QQ

1 Cairns J. The costs of prevention. BMf 1995;311:1520. (9 December.)

2 Rose G. Strategy of prevention: lessons from cardiovascular disease. $B M 7$ 1981;282:1847-51

3 Rose G. The population mean predicts the number of deviant individuals. $B M 7$ 1990;301:1031-4

4 Rose G. The strategy of preventive medicine. Oxford: Oxford University Press, 1992.

\section{Measurement of prostate specific antigen as screening test for prostate cancer}

\section{False positive results cast doubt on conclusion}

EDITOR,-Carol Parkes and colleagues' main conclusion that 60-74 year old men with a prostate specific antigen concentration $\geqslant 12$ times the normal median value have about a $50 \%$ chance of developing clinical prostate cancer within three years seems speculative and unsupported by the data presented. ${ }^{1}$ We are told that over the whole age range of the 49000 men studied 16 developed prostate cancer within three years of a blood sample being obtained, of whom 13 would have been detected if $\geqslant 12$ times the normal median concentration of prostate specific antigen was used as the cut off value. With this cut off $0.5 \%$ of the men-that is, about 245 (on the assumption that serum samples were available for most subjects) 